
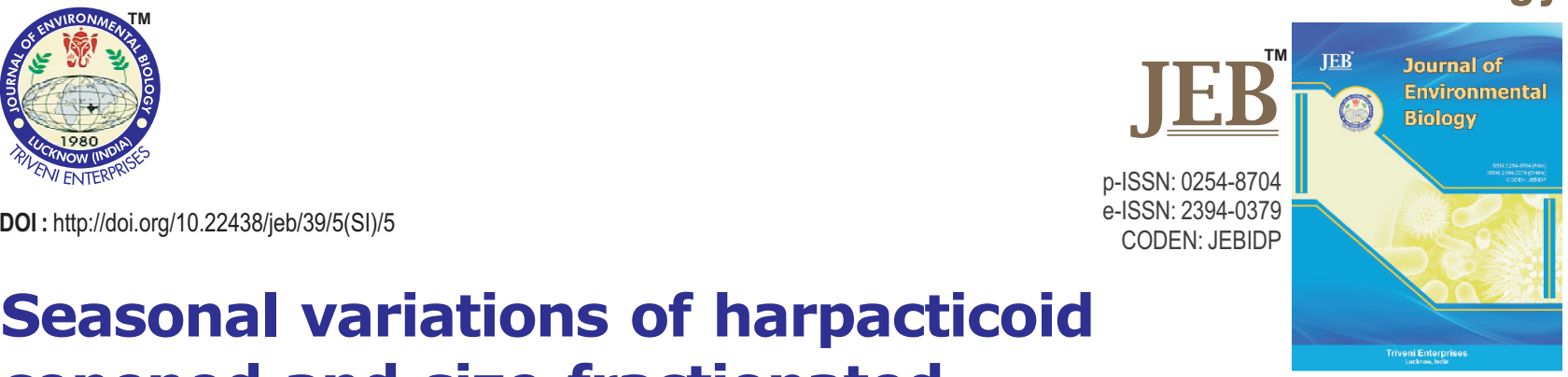

\title{
Seasonal variations of harpacticoid copepod and size-fractionated abundances in relation to environmental changes in Setiu Wetland
}

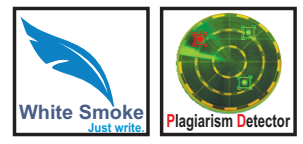

\section{Authors Info}

\section{N.F.S. Kamaruzaman ${ }^{1}$, Z. Kassim², S. Jasmani ${ }^{1}$ and N.F. Mohtar ${ }^{3 *}$}

${ }^{1}$ Institute of Aquaculture Tropical, Universiti Malaysia Terengganu, 21030 Kuala Nerus, Terengganu, Malaysia

${ }^{2}$ INOCEM Research Station, Kulliyyah of Science, International Islamic University Malaysia, 26160, Kuantan, Pahang, Malaysia

${ }^{3}$ School of Fisheries and Aquaculture Sciences, Universiti Malaysia Terengganu, 21030 Kuala Nerus, Terengganu, Malaysia

*Corresponding Author Email : fazliyana@umt.edu.my

Key words

Climate change Harpacticoid copepod Seasonal composition Setiu Wetland Tropical zooplankton

Publication Info

Paper received : 19.07 .2017

Revised received: 05.09.2017

Re-revised received : 25.11 .2017

Accepted : 28.12.2017

\section{Abstract}

Aim: Harpaticoid copepods, an important component of fauna in marine environment, play a vital role in aquatic food webs as a source of food for other member of benthic community and the juveniles of predator fish species. Recent data on benthic plankton and nekton composition in coastal wetland of Setiu are useful and important in understanding the interaction between these organisms at different seasons. This maintains the diversity of fish in Setiu Wetland which is a major factor in developing the Wetland as a place for ecotourism and recreational fishing activity. The effort will directly or indirectly benefit the fisheries community living within the wetland which depends on the fisheries sector.

Methodology: Meiobenthos samples were collected by Ponar grab. The samples were fixed in $10 \%$ formalin and 1\% Rose Bengal. Content of each specimen bottle was filtered through $102 \mu \mathrm{m}$ and $62 \mu \mathrm{m}$ sieve shaker, respectively. Harpacticoid were individually hand sorted and counted under dissecting microscope. Data obtained for harpacticoid composition were analyzed using Kruskal-Wallis test .

Results: Seasonal variation of harpacticoid composition for $100 \mu \mathrm{m}$ sizes recorded the highest number during pre-monsoon with 3591.84 ind $10 \mathrm{~cm}^{-2}$ followed by monsoon, 2569.68 ind $10 \mathrm{~cm}^{-2}$ and post-monsoon 1545.84 ind $10 \mathrm{~cm}^{-2}$, respectively. Salinity is the main physical parameters that can be attributed to the plankton diversity and acts as limiting factor that influences the distribution of plankton community. Significantly, harpacticiod copepod steadily increased during post-monsoon with rising trend of salinity verified the environmental influences on zooplankton abundances.

Interpretation: The results of this study indicated that different season demonstrated major impact on harpacticoid composition which may effect the avaibility of food source towards the small fishes as a live feed.
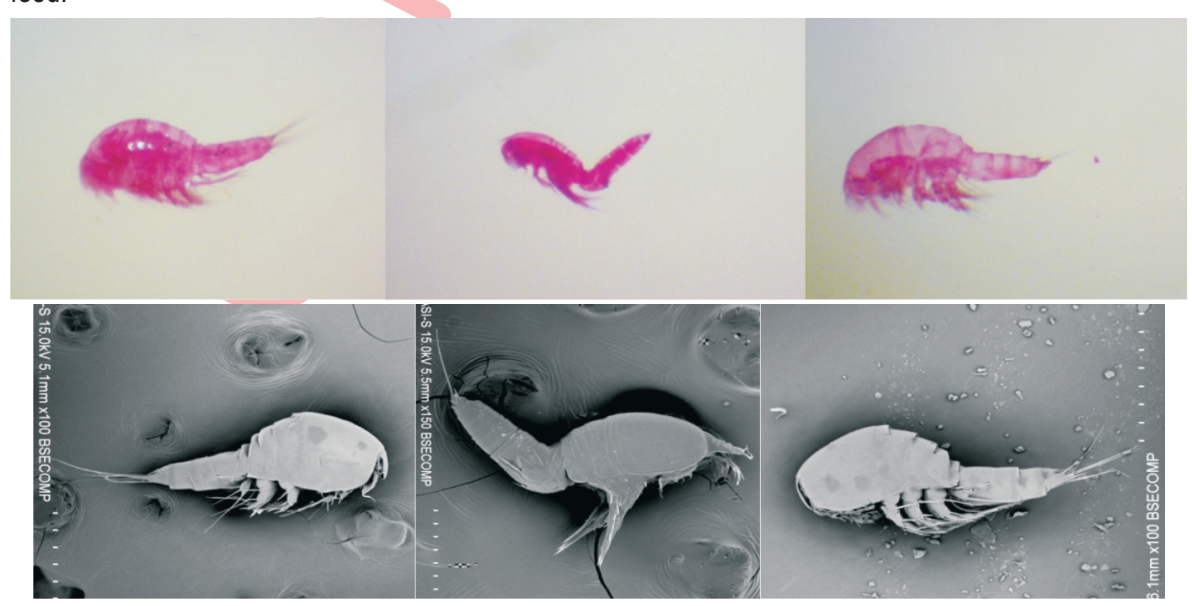

Several copepod species found at Setiu Wetlands under Compound microscope and Scanning Electron Microscope 


\section{Introduction}

Ecology is generally defined as the study that causes changes in the patterns of distribution and abundance of organisms. Many studies on the ecology of meiobenthos in the world have found that both abiotic parameters, such as oxygen content, temperature, salinity and $\mathrm{pH}$, as well as biotic parameters such as predation, competition and food availability, the influence the distributions and community structure (Armonies and Reise, 2002; Frisch et al., 2006). Harpacticoid copepods are considered as one of the most important components of the marine environment since they are a source of food for various members of meiobenthos, benthic macrofauna (Tita et al., 2005), as well as fish larvae (Buffan-Dubau and Carman, 2000). Due to their small size, they are rapidly affected by the changes in the biotic and abiotic environmental parameters, which may also affect larger organisms that depend on the meiobenthos as food source (Hack etal., 2007).

An estuary is a complex ecosystem that provides a favorable condition for aquatic organisms in terms of reproduction, nutrition and shelter (Reid and Wood, 1976). Seasonal factors can cause variations in the benthic community as studied by Hourstone et al. (2005) and Mok et al. (2015). Consequently, harpacticoid are subjected to daily and seasonal variations of water parameters, which strongly influence the distribution of benthic assemblages (Como and Magni, 2009). In this study, the composition and abundance of harpacticoid and other benthic fauna in the coastal wetland of Setiu at different seasons were determined.

Recent data on benthic plankton and nekton composition in coastal wetland of Setiu are useful and important in understanding the interaction between these organisms at different seasons. This maintains the diversity of fish in Setiu Wetland, which is a major factor in developing the Wetland as a place for ecotourism and recreational fishing activities. The effort will directly or indirectly benefit the fisheries community living within the wetland that greatly depend on the fisheries sector.

\section{Materials and Methods}

Sampling site : Sampling activities were carried at Setiu Wetland bimonthly for one year. The sampling area was divided into three stations, which included Station 1 (Brackish), Station 2 (Seagrass) and Station 3 (Estuary). The mouth of the estuary started from Station 3, and the salinity decreased towards Stations 2 and 1 (Fig. 1). Three different seasons were classed based on the mean daily rainfall (Malaysian Meteorology Department, 2016); Pre-monsoon (May, June, July and August) with a mean rainfall of $856.70 \mathrm{~mm}$, Monsoon (September, October, November, December), of $1425.60 \mathrm{~mm}$ and Postmonsoon (January, February, March and April) of $579.40 \mathrm{~mm}$ during entire sampling period.

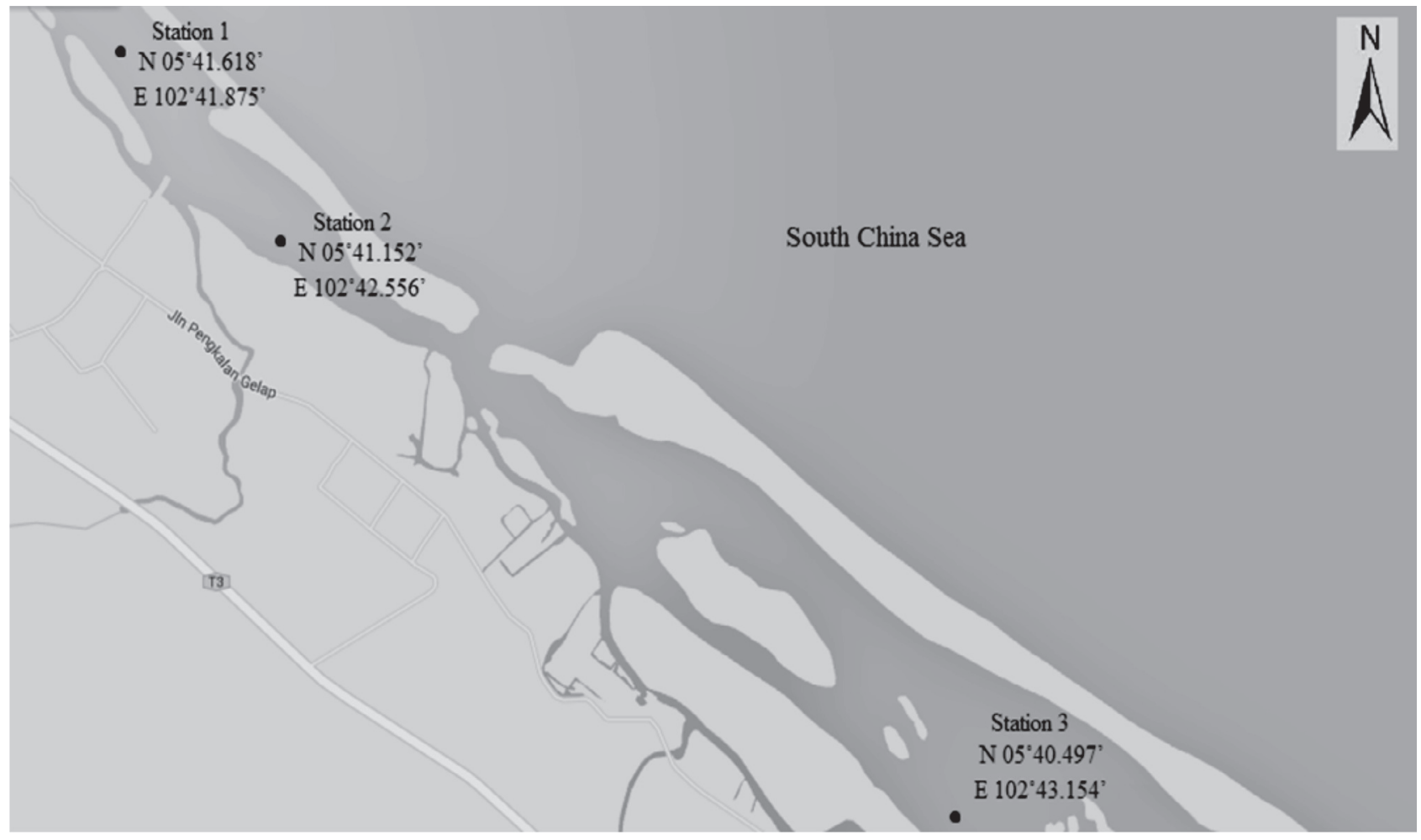

Fig. 1 : Location of Setiu Wetland showing the sampling stations 
Field sampling : Meiobenthos samples were collected with a Ponar grab. Sediments from the Ponar grabber were placed on a flat tray and subsampling was carried out by using a specimen bottle. The samples were fixed in $10 \%$ formalin and $1 \%$ Rose Bengal. Three replicates of sediment samples were collected from each station.

Harpacticoid copepod analysis : The contents of each specimen bottle was filtered through a $102 \mu \mathrm{m}$ and $62 \mu \mathrm{m}$ sieve shaker, respectively, to remove algal fronds, any larger organisms and to separate different sizes of harpacticoids. Harpacticoids and other benthic fauna were individually hand sorted and counted under a dissecting microscope.

Data analyses : Data obtained for the harpacticoid composition were analyzed using Kruskal-Wallis test. The seasonal relationships and environmental variables were analyzed using a Spearman rank correlation $(r)$ and regression $\left(r^{2}\right)$. Statistical analyses were carried out using SPSS version 18.0.

\section{Results and Discussion}

The seasonal variation of harpacticoid composition for 100 $\mu \mathrm{m}$ sizes recorded the highest number during pre-monsoon with 3591.84 ind $10 \mathrm{~cm}^{-2}$ followed by monsoon, 2569.68 ind $10 \mathrm{~cm}^{-2}$ and post-monsoon 1545.84 ind $10 \mathrm{~cm}^{-2}$, respectively, as shown in Fig. 2 .

There were significant differences of the harpacticoid composition between pre-monsoon and post-monsoon $(p \leq 0.05)$. However, there was no significant difference observed between monsoon and post-monsoon $(p>0.05)$. The seasonal variation in the present study is in accordance with Bode et al. (2005) who found that plankton abundance, composition and biomass were influenced by seasonal variability of the plankton bloom. Meanwhile, for $60 \mu \mathrm{m}$ sized harpacticoids the highest composition was recorded during monsoon at 787.93 ind $10 \mathrm{~cm}^{-2}$, followed by pre-monsoon, 534.75 ind $10 \mathrm{~cm}^{-2}$ and post-monsoon 392.40 ind $10 \mathrm{~cm}^{-2}$. Harpacticoid abundance had a strong negative correlation with seasons $(r=0.177 ; p<0.01)$. Regression analysis also showed a negative relationship $\left(r^{2}=0.090\right)$.

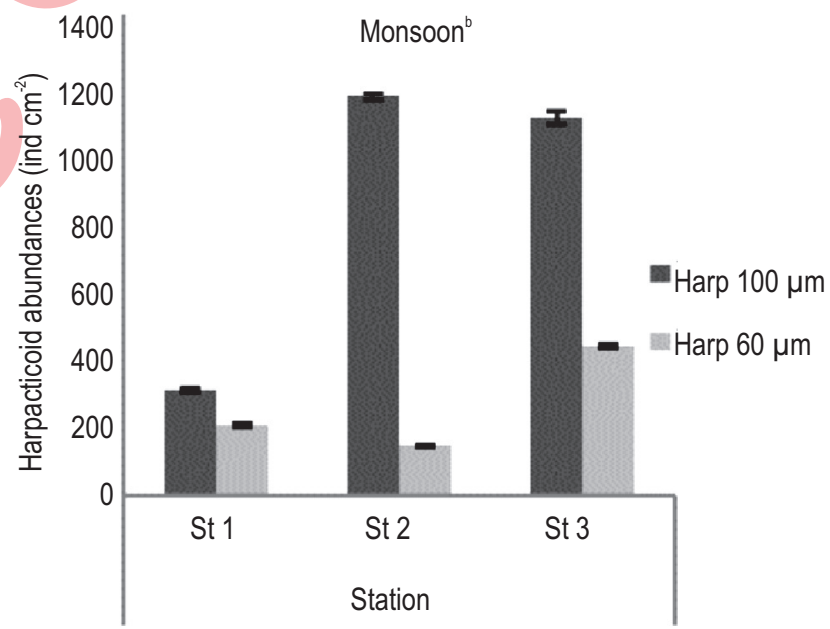

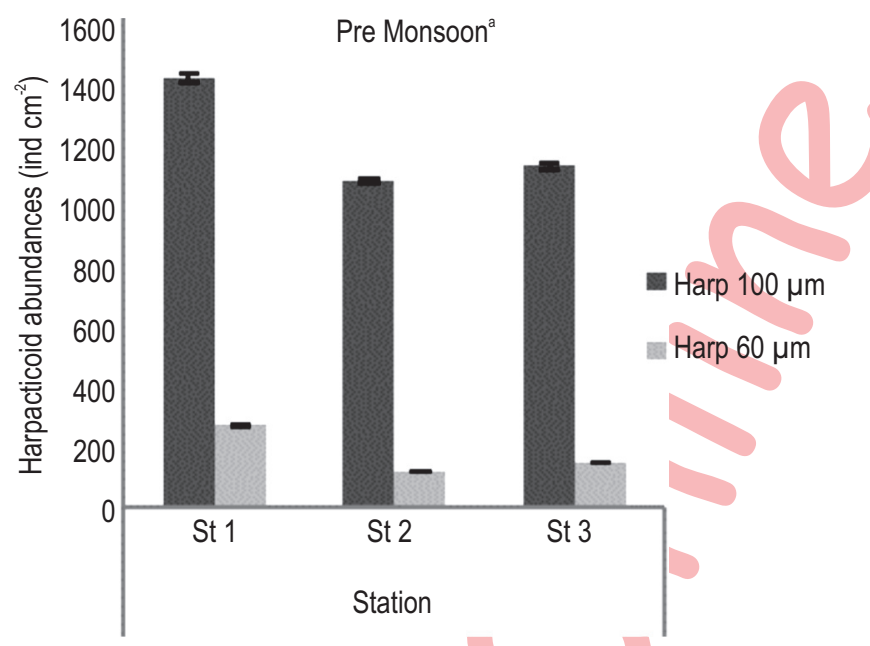

Post Monsoon

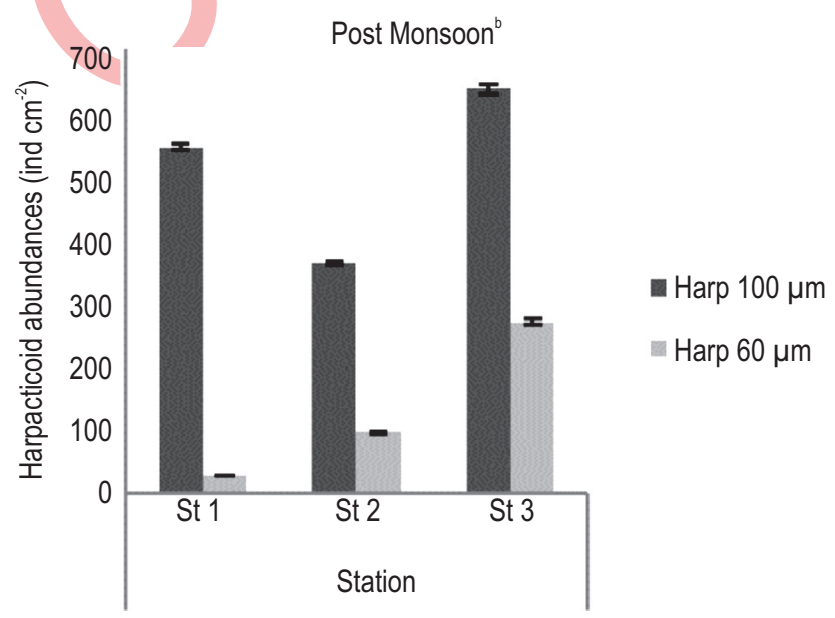

Fig. 2 : Harpacticoid abundances during Pre-Monsoon, Monsoon and Post-Monsoon as Setiu Wetland. The superscript alphabets (a and b) represent significant differences of harpacticoid composition 
Table 1: Water parameters during Pre-Monsoon, Monsoon and Post-Monsoon at Setiu Wetland

\begin{tabular}{llllll}
\hline Season/Parameters Station & Temperature $\left({ }^{\circ} \mathrm{C}\right)$ & Salinity $(\mathrm{ppt})$ & $\mathrm{pH}$ & $\mathrm{DO}\left(\mathrm{mgl} \mathbf{l}^{-1}\right)$ \\
\hline Pre-Monsoon & Station 1 & $30.41 \pm 0.78$ & $27.05 \pm 2.10$ & $6.32 \pm 1.13$ & $6.73 \pm 1.93$ \\
& Station 2 & $30.77 \pm 0.83$ & $28.50 \pm 1.09$ & $5.98 \pm 0.98$ & $6.90 \pm 1.98$ \\
& Station 3 & $30.33 \pm 0.70$ & $29.31 \pm 0.64$ & $6.09 \pm 1.24$ & $7.32 \pm 1.17$ \\
Monsoon & & & & \\
& & & & & \\
& Station 1 & $29.77 \pm 0.85$ & $16.28 \pm 7.46$ & $5.97 \pm 1.41$ & $6.17 \pm 0.72$ \\
Post-Monsoon & Station 2 & $27.93 \pm 2.79$ & $18.88 \pm 8.03$ & $6.21 \pm 1.37$ & $6.66 \pm 1.33$ \\
& Station 3 & $29.92 \pm 0.75$ & $19.55 \pm 8.25$ & $6.30 \pm 1.24$ & \\
& & & & & \\
& Station 1 & $30.07 \pm 0.76$ & $19.87 \pm 6.94$ & $7.51 \pm 0.49$ & $4.26 \pm 0.46$ \\
& Station 2 & $30.47 \pm 0.57$ & $22.27 \pm 6.79$ & $7.68 \pm 0.46$ & $4.87 \pm 0.25$ \\
\end{tabular}

The composition of harpacticoid copepods was relatively varied depending on the season, which indicates that this copepod species reflects the characteristics of the associated abiotic parameters as claimed by Paturej (2009); in which zooplankton are frequently used as biotic indicators of water quality. Salinity (ppt) was highly varied throughout the season as shown in Table 1. The lowest salinity was found at $18.23 \pm 0.69 \mathrm{ppt}$ during monsoon and increased slightly at post-monsoon to $21.63 \pm 0.62 \mathrm{ppt}$, which then continued to increase at premonsoon to $28.27 \pm 0.16 \mathrm{ppt}$.

Water parameters are likely affected by the abundance of harpacticoids. Salinity was the most important parameter, which positively affected the variation of harpacticoids $(r=0.189 ; p<$ 0.01 ) followed by temperature and dissolved oxygen ( $r=0.160 ; p$ $<0.01, r=0.140 ; p<0.01$ respectively). In contrast, $\mathrm{pH}$ demonstrated a negative correlation $(r=0.129 ; p<0.01)$ towards the seasonal variance of the harpacticoid composition. Increased salinity that occurred from Station 1 towards Stations 2 and 3 contributed to increasing the number of harpacticoids recorded and a positive correlation $(r=0.019, p<0.01)$ with salinity was observed. Johan et al. (2012), Stephen et al. (2012) and Johnshon et al. (2011) also reported a positive correlation with salinity, in which, such findings were in good agreement with our results. On the other hand, Paula et al. (2001) suggested that seagrass (Station 2) is where intertidal vegetated habitats are known to provide food sources, thus attracting mobile organisms.

Other fauna such as planktonic copepods, polychaetes, nematode, and amphipods were also observed (Fig. 3). During pre-monsoon, the abundance of other benthic fauna were lowest at 153 ind $10 \mathrm{~cm}^{-2}$, but increased in post-monsoon to 220 ind 10 $\mathrm{cm}^{-2}$ and reached the highest level at 239 ind $10 \mathrm{~cm}^{-2}$ during monsoon.

There were significant differences observed in salinity between the seasons $(p \leq 0.05)$, which would play a major role in

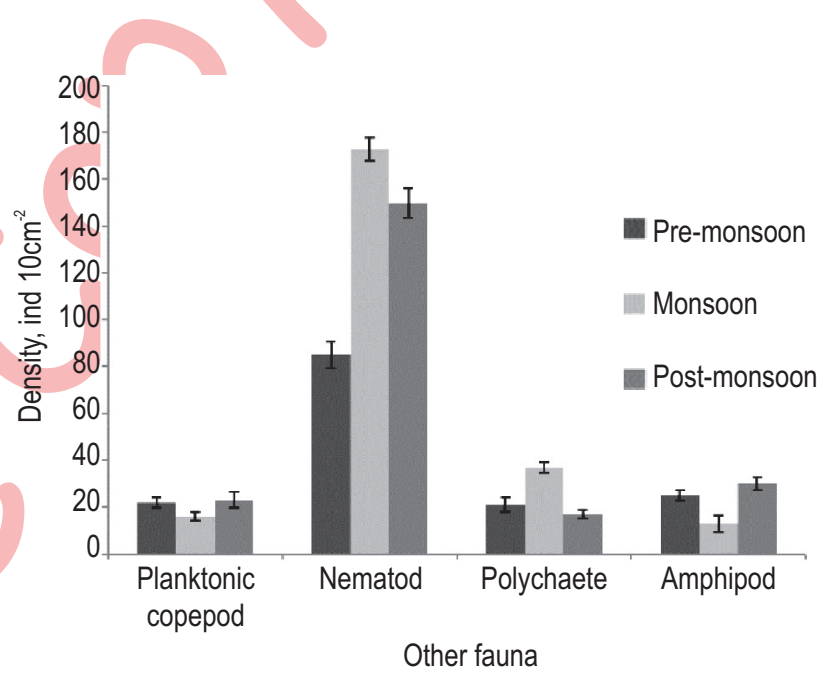

Fig. 3 : Other fauna density during Pre-Monsoon, Monsoon and PostMonsoon at Setiu Wetland

influencing the harpacticiod composition. Monsoon seasons highly affects salinity along the Setiu Wetland. The composition of harpacticoids tends to increase during pre-monsoon due to high water salinity, indicating that most of the species were of oceanic origin (Tam et al., 2000).

Temperature and dissolved oxygen fluctuation do not have significant impacts on species composition (Sridhar et al., 2006; Selleslagh et al., 2012). Conversely, salinity is the main physical parameters that can be attributed to the plankton diversity and acts as a limiting factor that influences the distribution of plankton community. This aspect is supported by Ahmed et al. (2014) who claimed that decreasing salinity cause a stress condition, resulting in loss of biodiversity. Johan et al. (2012) also indicated that copepod species, abundance and diversity were highly correlated with salinity, but had little interactions with dissolved oxygen and $\mathrm{pH}$. 
The highest number of other benthic fauna, which was highly dominated by amphipods followed by nematodes, was observed during the monsoon at the end of the season. This indicates that as the temperature and salinity increased, amphipods became highly distributed. Qin et al. (2014) stated that salt marshes are the main source of amphipods and this is further supported by the findings from Mazumder et al. (2009). In contrast, the scenario where different species dominated in any season, indicates a wide variability in species composition of benthic fauna over time. Significantly, harpacticiod copepods steadily increased during the post-monsoon with rising trend of salinity, which verified that this abiotic factor influences zooplankton abundance.

The results of this study indicate that different seasons have a major impact on the composition of harpacticoids and other benthic fauna, with salinity having the greatest affect on abundance of benthic harpacticoid copepods. Therefore, the current findings on the seasonal harpacticoid composition reported from Setiu Wetland is very important because they are able to present the trend of seasonal variation. Studies on the seasonal distribution of harpacticoids is highly necessary to maintain the diversity and further help fish population management in the Setiu Wetland as they serve small fishes as a live feed.

\section{Acknowledgments}

Special thanks are extended to the Universiti Malaysia Terengganu. This project was financially supported by the Niche Research Grant Scheme NRGS/2014/53131/15.

\section{References}

Ahmed, M.M.H., R.Z.T. Hermine, M.A.H. Maged, K.H. Samia, A.A. Nagwa and M.G. Samiha: Potential effects of abiotic factors on the abundance and distribution of the plankton in the Western Harbour, South-Eastern Mediterranean Sea, Egypt. Oceanologia, 8, 3-13 (2014).

Armonies, W. and K. Reise: Faunal diversity across a sandy shore. Mar. Ecol. Prog. Ser., 196, 49-57 (2000).

Bode, A., M. Teresa, O.A. Lvarez, S.G.L. Nicola, J. Lorenzo, R.G. Cristina, V. Manuel and M.V. Marta: Seasonal variability of plankton blooms in the Ria De Ferrol (NW Spain): II. Plankton abundance, composition and biomass. Estuar. Coast. Shelf Sci., $63,285-300$ (2005).

Buffan, D.E. and K.R. Carman: Diet feeding behavior of meiofauna and their relationships with microalgal resources. Limno. Oceanogr., 45, 381-395 (2000).

Como, S. and P. Magni: Temporal changes of a macrobenthic assemblage in harsh lagoon sediments. Estuar. Coast. Shelf Sci,, 83, 638-646 (2009).

Frisch, D., M.O. Enrique and J.G. Andy: Species richness and distribution of copepods and cladocerans and their relation to hydroperiod and other enviromental variables in Donana, SouthWest Spain. Hydrobiol., 556, 327-340 (2006).
Hack, L.A., L.A. Trembley and S.D. Wratten: Benthic meiofauna community composition at polluted and non-polluted sites in New Zealand intertidal environments. Mar. Poll. Bull., 54, 1801-1812 (2007).

Hourstone, M., R.M. Warwich, F.J. Valesini and I.C. Potter: To what extent are the characteristics of nematode assemblages in the nearshore sediments on the West Australian Coast related to habitat type, season and zone? Estuar. Coast. Shelf Sci., 64, 601612 (2005).

Johan, I., M.W.O. Wan, M. Mashhor, H.M.K. Abu and S.M.N. Amin: Spatial distribution of copepod along the salinity gradient of Perai River Estuary, Penang, Malaysia. J. Biol. Sci., 13, 647-652 (2012).

Johnson, C. L., J.A. Runge, K.A. Curtis, E.G. Durbin and J.A. Hare: Biodiversity and ecosystem function in the Gulf of Maine: Pattern and role of zooplankton and pelagic nekton. J. Pone., 6, 16491 (2011).

Mazumder, D., N. Saintilan and R.J. Williams: Zooplankton inputs and outputs in the saltmarsh at Towra Point Australia. Wetl. Ecol. Manage., 17, 225-230 (2009).

Mok, H.K., J.X. Liao and H.M. Yeh: Meiofaunal communities in a tropical seagress bed and adjedcent unvegetated sediments with note on sufficient sample size for determining local diversity indices. Zool. Stud., 54, 14 (2015).

Paturej, E.: A zooplankton study of coastal lakes. Balti. Coast. Zon., 13, 25-32(2009).

Paula, J., C.P. Fidalgo, A. Martins and D. Gove: Patterns of abundance of seagrasses and associated infaunal communities at Inhaca Island, Mozambique. Estuar. Coast. Shelf. Sci., 53, 307-318 (2001).

Qin, H., Q. Sheng, T. Chu, S. Wang and J. Wu: Import and export fluxes of macrozooplankton are taxa- and season-dependent at Jiuduansha Marsh, Yangtze River Estuary. Estuar. Coast. Shelf Sci., 14, 1-11 (2014).

Reid, G.K. and R.D. Wood: Ecology of Inland Waters and Estuaries. $2^{\text {nd }}$ Edn., Van Nostrand, D. New York (1976).

Selleslagh, J., J. Lobry, A. R. N'Zigou, G. Bachelet, H. Blanchet, A. Chaalali, B. Sautour and P. Boet: Seasonal succession of estuarine fish, shrimps, macrozoobenthos and plankton: Physicochemical and trophic influence. The Gironde Estuary as a case study. Estuar. Coast. Shelf Sci., 112, 243-254 (2012).

Sridhar, R. T., S. Thangaradjou, K. Senthil and L. Kannan: Water quality and phytoplankton characteristics in the Palk Bay, South-East Coast of India. J. Environ. Biol., 27, 561 - 566 (2006).

Stephen, M. B., K. B. Joanne, R. C. Jeffery, R. B. Gretchen and K. Olga: Invasive copepods in the lower Columbia River Estuary: Seasonal abundance, co-occurrence and potential competition with native copepods. Aqua. Inva., 7, 101-109 (2012).

Tam, P.F., C.K. Wong, Q. Chen, Y. Fu, L. Huang and J. Yin: Planktonic copepod of the Zhujiang Estuary, 1991 - 1996. Proc. Inter. Symp. Mar. Biol. in Taiwan, 10, 156-164 (2000).

Tita, G., C. Nozals and R. Perrissinotto: Seasonal dynamics of meiofauna in a South African temporarily open/closed estuary (Mdloti Estuary, Indian Ocean). Estuar. Coast. Shelf Sci., 62, 325338 (2005).

Yoshida, T., P.H. Matias, M.D.Y. Fatimah, T. Toda and O.B.H. Ross: Zooplankton research in Malaysia: Current status and future prospects. Coast. Mar. Sci., 35, 208-213 (2012). 